\title{
Los “judíos progresistas" entre el retorno del peronismo y la dictadura militar en Argentina a través de la prensa (1973-1976)
}

"Progressive Jews" between the return of peronism and the last military dictatorship in Argentina through the press (1973-1976)

Dr. Emmanuel Nicolás Kahan emmanuel.kahan@gmail.com Universidad Nacional de La Plata Argentina

\section{Resumen}

Como corolario a la Guerra de los Seis Días (1967) y las repercusiones en el debate político que suscitó aquella contienda bélica en Argentina, la Federación de Instituciones Culturales Judías de la República Argentina, el ICUF, promovió una nueva publicación desde la cual daría a conocer sus diversos posicionamientos frente a conflictos de diversa índole: la situación en Medio Oriente, la vida cultural judía en la Unión Soviética, los conflictos de las organizaciones comunitarias locales y el estado de la situación política, económica y cultural en Argentina. Desde entonces y hasta 1987, cuando deja de editarse la publicación icufista, las páginas de Tiempo serían testimonio de las transformaciones y continuidades de la conflictividad política al interior de los ámbitos comunitarios y, a su vez, de las tensas relaciones y configuraciones de sentidos de la política nacional argentina.

El presente trabajo indagará en los diversos posicionamientos y narrativas que esgrimieron los redactores de Tiempo durante un período singular de la historia política argentina: desde 
la asunción presidencial de Héctor Cámpora (1973) hasta el inicio de la última dictadura militar en Argentina (1976).

Palabras Clave: Judíos - Comunistas - Argentina - Peronismo.

\begin{abstract}
As a corollary of the Six Days War and its repercussions in the Argentinean political debate, the Federación de Instituciones Culturales Judias de la República Argentina, the ICUF, launched a new publication from which its members would express their position with regard to conflicts of diverse nature: the Middle-East situation, Jewish cultural life in the USSR, conflicts among local communal organizations, and the political, economical and cultural situation in Argentina. Since then and until 1987, when the Icufist periodical stopped being published, Tiempo's pages would provide testimony of the transformations and the continuities about the political conflict within the community's spaces and, simultaneously, about the tense relationships and meaning configurations established with the Argentinean national political stage.
\end{abstract}

This paper will examine the diverse positions and narratives wielded by the wordsmiths of Tiempo during a peculiar period of Argentinean political history: from Héctor Cámpora's presidential inauguration (1973) to the beginning of the last military dictatorship (1976).

Keywords: Jews - Communist - Argentina - Peronism. 


\section{La Revista Tiempo: vocera de "los sectores progresistas de la comunidad judía en} Argentina"

La primera mitad del siglo XX es abundante tanto en acontecimientos que ponen a la comunidad judía argentina en el centro de la escena pública -la Semana Trágica (1919) (Lvovich, 2003) y el desbaratamiento de la organización Zwi Migdal (1930) (Guy, 1994; Yafitz, 2011), por ejemplo- como en la conformación de entidades que intentan centralizar la representación de la vida comunitaria frente al Estado nacional. Como señala Silvia Schenkolewski-Kroll (1993), las disputas entre los diversos idearios que componen los espacios institucionales y representativos de la vida judía en Argentina comienzan en una época temprana.

Hacia fines del siglo XIX podemos encontrar organizaciones vinculadas a tendencias ideológicas que producían algunas respuestas acerca de la particularidad de la experiencia judía en la Diáspora: el Idisher Arbeiter Farain far Guegnzaitiquer (Centro Obrero Judío de Ayuda Mutua) y el Jovevei Zión (Joven Sión) son algunas de ellas. Sionistas y "progresistas" se disputarán el reconocimiento como productores de sentidos legítimos de la comunidad judía. La confrontación en pos de obtener la conducción de sus instituciones centrales tendrá su momento disruptivo en el año 1952, cuando en las elecciones para designar las autoridades de la Asociación Mutual Israelita Argentina (AMIA), el frente de agrupaciones sionistas intimó a los "progresistas" de ICUF (Idisher Cultur Farband o Unión Cultural Judía) a condenar los procesos contra intelectuales y artistas judíos en la URSS. ${ }^{1}$ Esta organización, ligada al Partido Comunista Argentino, decide -al negarse a realizar esa condena- abandonar la confrontación por la conducción de las instituciones centrales de la comunidad organizada. (Svarch, 2005)

Este sector "progresista" de la vida comunitaria judía en Argentina encuentra sus antecedentes en el proceso formativo del Partido Comunista en 1920. Como ilustra Camarero (2007, pp.297-311), durante su período fundacional el partido promoverá la

\footnotetext{
${ }^{1}$ Si bien no formará parte del corpus a ser analizado en este trabajo, resulta significativo que el tema de los "poetas judías asesinados en la URSS" continuo siendo un tema de debate entre los diversos actores comunitarios durante el período estudiado en este trabajo.
} 
creación de "Secciones Idiomáticas" destinadas a captar la participación de los obreros inmigrantes. Los judíos se agruparon en la Ievsekzie -Idishe Sektzie des Komunistishes Partei o sección Judía del Partido Comunista-, promoviendo la acción en el ámbito gremial y cultural, creando bibliotecas y conformando elencos de teatro. Aunque esta sección desaparece en la década del '30, el grupo, que se denominó como "progresista", mantuvo los vínculos con el Partido, primero informalmente, y luego a través del ICUForganización creada en 1941. (Svarch, Op. Cit.)

Desde una temprana época, el sector autodenominado "progresista", tuvo una fuerte impronta educativa y cultural. Como señala Svarch, la Ievsekzie fue la única sección idiomática del Partido Comunista Argentino (PCA) que logró fundar su red escolar propia: Arbeter Shul Organisatzie (Organización de Escuelas Obreras) o Arbshulorg. Asimismo, los miembros de la sección idiomática yidishista ${ }^{2}$ del PCA constituyeron diversos centros donde tendieron a agruparse: bibliotecas populares, clubes obreros, sociales y deportivos.

Como destaca Dujovne (2008), las iniciativas editoriales al interior del campo judío progresista tuvieron un papel destacado. Roiter Shtern (Estrella Roja), el periódico en yidish de la Ievsekzie, que se publicó entre 1923 y 1934, tenía una tirada mayor al Ordine Nuovo, a pesar de que la sección italiana del PCA era la más numerosa. ${ }^{3}$ Asimismo, la Sociedad de Ayuda a Colonos Israelitas en la Rusia Soviética ${ }^{4}$, entidad conocida bajo la

\footnotetext{
${ }^{2}$ Dialecto de los judíos ashkenazím.

${ }^{3}$ Como señala Hernán Camarero (Op. Cit., p.302), "Hacia octubre de 1927, Roiter Shtern publicaba más de tres mil quinientos (números); era el órgano de prensa comunista con mayor tirada luego del oficial en castellano La Internacional, que editaba seis mil ejemplares. Para ese mismo momento, también se publicaban unos mil ejemplares mensuales del periódico infantil comunista El Pioner, también escrito en yidish, y otros mil quinientos de una revista mensual llamada Naivelt (Nuevo Mundo). Los comunistas reconocían al yidish como un idioma popular en vigencia y lo escribían por su pronunciación, no por su raíz hebrea, lengua que rechazaban".

${ }^{4}$ Siguiendo a Ariel Svarch (Op. Cit.) podemos definir al PROCOR como una "institución, que existía también en otros países, (que) nació como la alternativa de Moscú al proyecto sionista de un Estado propio: la solución comunista, como no podía ser de otra manera, estaba en la URSS. El proyecto consistía en la colonización agrícola de territorios vacíos de Rusia o sus satélites, como la solución para el problema de las "masas judías desclasadas", en un intento por volverlas productivas e integrarlas al cuerpo de los trabajadores y campesinos, salvándolas así de su destino pequeñoburgués. Funcionaba, entonces, como una versión soviética del "Keren Kayemet LeIsrael", el fondo agrícola sionista que recaudaba fondos para comprar tierras y establecer colonias en Palestina. PROCOR, de hecho, pedía como donación parte de la cosecha a los judíos de las colonias
} 
sigla de PROCOR, editó una revista mensual llamada Naierd (Nuestra Tierra). A su vez, una de las "fracciones idiomáticas sindicales" del PCA, la Federación Obrera del Vestido editó, hacia 1926, Der Confektion Arbeter (El Obrero de la Confección).

No obstante, la actividad desplegada por los "judíos comunistas" se vio permeada por las tensiones que fueron propias del derrotero institucional y político argentino. De esta manera, cada vez que una medida de gobierno suspendía o prohibía las actividades del PCA, las acciones desarrolladas por los "progresistas" tendían a "camuflarse" u organizarse clandestinamente (Zadoff, 1995; Svarch, Op. Cit; Kahan, 2013; Visacovsky, 2015). Debido a la persecución de la que fuera parte el PCA por la escalada represiva del régimen instaurado por el General José Félix Uriburu durante la década del ‘30, por ejemplo, las actividades de la Ievsekzie tendieron a ser clausuradas y/o debieron recrearse en ámbitos y formas clandestinas.

En 1941, tras el golpe de timón de la III Internacional Comunista ${ }^{5}$ y la celebración del Congreso en Defensa de la Cultura Judía, que tuviera lugar en 1937 en la ciudad de París, se constituyó una nueva asociación aglutinante del "judaísmo progresista" en Argentina: la Federación de Instituciones Culturales Judías de la Argentina o ICUF (Idisher Cultur Farband). Sin embargo, en contraste con la Ievsekzie, como indica Svarch, esta organización tenía un carácter distinto: la relación con el PC no era obvia ni explícita. En teoría, el ICUF no era más que una red de instituciones judías laicas. Y, a diferencia de la impronta "obrerista" de la "sección idiomática yidishista del PCA", el ICUF se lanzaría a competir por la dirección de las instituciones judías centrales.

El ICUF agrupó instituciones preexistentes como al Idisher Folks Teater (IFT - Teatro Popular Judío), varias organizaciones de residentes (oriundos de Varsovia y Lodz, por

argentinas, al igual que el KKL. También tenía sus socios que contribuían mensualmente, y celebraba eventos y cenas para recaudar fondos".

5 "Luego de 10 años de bregar por la lucha de clases sin cuartel ni alianzas, el ascenso del fascismo en Italia y Alemania determinaron la adopción de una nueva estrategia: la del Frente Popular. Moscú recomendaba a los partidos comunistas del mundo que se aliaran con todo el arco democrático liberal, desde socialdemócratas hasta conservadores, para hacer causa común contra el enemigo mutuo fascista”. (Svarch, Op. Cit.) 
ejemplo), al menos un hogar de ancianos (Méndele), el club social y deportivo Sholem Aleijem, y creó su propia red de escuelas. Asimismo, como su antecesora, contó con numerosas publicaciones: las revistas culturales ICUF (hasta 1950) y Aporte (1953-1956), Nai Teater (Nuevo Teatro) del IFT; los periódicos Folks Shtime (La voz del Pueblo) y Tribuna; las publicaciones bilingües De Idische Froi (La Mujer Judía) y Landsmannschaft (Tierra de Origen).

La revista mensual Tiempo comenzó a publicarse el 30 de julio de 1968 y concluyó su edición hacia 1987. Según consta en cada uno de los números editados, su directorpropietario fue Julio Schvenderfinger. No obstante, como indica él mismo en una entrevista realizada por Beatriz Kessler (2008), Schvenderfinger se consideró un "presta-nombre". Según el director del mensuario, el verdadero mentor de la iniciativa de Tiempo fue Rubén Sinay, "una pluma magnífica, un periodista con todo lo necesario". 6

Tiempo constituye una publicación relevante para el análisis del sector "progresista" de la vida comunitaria judía en Argentina. Como puede observarse desde su primer ejemplar, los temas abordados son considerablemente amplios: entrevistas a Abelardo Castillo, Emilio Troise y José Itzigsohn acerca de "la paz en Medio Oriente", la situación política y económica en Argentina, acontecimientos de la vida comunitaria local, el antisemitismo, la situación de la colectividad judía en otros países y artículos sobre literatura, cine y diversas perspectivas culturales. Su programa editorial alentaba:

(El) diálogo y la comunicación entre la gente democrática de la colectividad judeoargentina. (...) Los iniciadores de TIEMPO sustentan criterios precisos acerca de las causas de los problemas y de las soluciones correspondientes. Consideran que la realidad histórica de nuestra colectividad y sus posibilidades de pleno desarrollo en las diferentes esferas de la actividad constructiva y creadora están condicionadas al reinado

\footnotetext{
${ }^{6}$ Rubén Sinay fue uno de los redactores y conspicuos “intelectuales” del ICUF. Asimismo, constituyó uno de los polemistas más acérrimos con otros referentes de las asociaciones sionistas en Argentina. (Kahan, 2005)
} 
de la democracia y a la renovación progresista de las estructuras socio-económicas del país; que los peligros externos de específico signo antijudío, en inquietante incremento, responden en último análisis a la vigencia de condiciones generales lesivas para los intereses populares y propicias para las acciones reaccionarias; que la capacidad de resistencia de la colectividad ante el enemigo exterior y sus aptitudes para desplegar fecundas $y$ diversificadas actividades creadoras que consoliden material y espiritualmente sus defensas, se ven minadas por las rupturas y defensas internas, las intolerancias, las prácticas antidemocráticas en el funcionamiento de las entidades representativas, las tendencias sectarizantes con objetivos de monopolización política e ideológica y, sobre todo, por el desencuentro y estamentación (sic) artificial de las mayoritarias y decisivas fuerzas democráticas y progresistas”. (Por qué Tiempo. Tiempo, 1, 3, 30 de julio de 1968)

Al menos programáticamente, los redactores de Tiempo afirman que el destino de la "vida comunitaria" dependía de lo que acontecía en un plano más "nacional" de las prácticas políticas. Que "el reinado de la democracia y la renovación progresista de las estructuras socio-económicas" (Op. Cit.) sería el marco para el desarrollo de la dinámica institucional, cultural y política de la experiencia judía en Argentina. Y que, frente a estos desafíos, que implicaban la participación de los judíos en los procesos políticos que se desarrollaban en el país, la dinámica institucional de la colectividad debería renovarse y ampliar democráticamente su espectro de voces reconocidas.

Pero, en consonancia con los avatares del derrotero político argentino, Tiempo fue testigo de un largo y conflictivo proceso en el que se cuentan dictaduras militares, el retorno del peronismo a la esfera gubernamental, la transición democrática iniciada en 1983 y los 
debates en torno de la responsabilidad de las Fuerzas Armadas en la perpetración del terrorismo de Estado que dejó como saldo 30.000 detenidos-desaparecidos.

\section{“Cámpora al gobierno, Perón al poder”: posicionamientos y representaciones de los sectores dirigentes del ICUF frente al tercer gobierno peronista}

El período inaugurado por el triunfo del Frente Justicialista de Liberación (FREJULI) y la posterior asunción de la presidencia de Héctor Cámpora -es decir, la llegada al poder del peronismo tras dieciocho años de proscripción- fue concebido como la apertura de un proceso institucional que encauzaría la alta conflictividad social y política que caracterizó a la Argentina desde la década del sesenta -aún más tras el Cordobazo ${ }^{7}$ (1969) y el fusilamiento del General Pedro Eugenio Uriburu por parte de la organización políticomilitar Montoneros (1970). ${ }^{8}$

Sin embargo, como describe De Riz (2000), los incidentes cercanos a la Plaza de Mayo ${ }^{9}$, el mismo 25 de mayo de 1973, durante los actos de la asunción presidencial y la posterior sanción de un decreto presidencial que amnistiaba a los "presos-políticos" de las dictaduras de Ongañia y Lanusse (1967-1973), evidenciaría que la conflictividad política estaría lejos de aquietarse. Cómo se interroga De Riz, “AAcaso ese descontrol de la movilización popular era el presagio de los tiempos que se avecinaban?” (De Riz, Op. Cit, p.123)

No obstante, el fin de la dictadura lanussista y el retorno al poder del peronismo, fueron vistos con extremo entusiasmo: "En 1973, la confianza de los electores en la fórmula del peronismo se nutría de una mezcla de nostalgia del pasado y de esperanza por un futuro que cambiará el destino del país y, tal vez, de sus propias vidas” (Op. Cit.) Incluso, como muestran Cernadas y Tarcus (2005), sectores que en sus orígenes habían denostado al

\footnotetext{
${ }^{7}$ Un alzamiento popular ocurrido en la ciudad de Córdoba, el 29 de mayo de 1969, tras el asesinato del estudiante Máximo Mena.

${ }^{8}$ Montoneros fue una organización política-militar ligada al peronismo que actuó desde 1969 hasta los últimos jalones de la dictadura militar en Argentina. Ver: Lanusse, 2005.

${ }^{9}$ Durante los actos protocolares de asunción de la magistratura presidencial se insultaba a los miembros de las Fuerzas Armadas que se encontraban cercanas a la Plaza de Mayo, gritándoles "Se van, se van y nunca volverán".
} 
peronismo mostraban un carácter de renovada satisfacción frente a la victoria del Frente Justicialista por la Liberación (FREJULI) el 11 de marzo de 1973.

Imbuida del mismo optimismo de época, aunque atendiendo a la particularidad de sus posicionamientos en el "frente interno" de la comunidad judía argentina, el ICUF sostenía, en una solicitada publicada en la revista Tiempo, que:

La Federación de Entidades Culturales Judías - ICUF- expresa la honda satisfacción de los sectores democráticos de la colectividad judía del país por el restablecimiento de las normas constitucionales de la República, la asunción del poder por un gobierno de legítima representatividad popular y la iniciación de una etapa en la vida nacional pletórica de posibilidades de transformación progresista. (...) La participación de la Federación de Entidades Culturales Judías en los procesos sociales que conmueven a la Nación, responde a una posición de principios, según los cuales los grandes problemas que preocupan a los sectores democráticos y laboriosos de la colectividad están en íntima e indisolublemente ligados a los decisivos problemas generales. (...) Esta comunión de intereses dio sentido y plenitud al júbilo de los sectores democráticos de la colectividad por los primeros pasos positivos del gobierno constitucional, consistentes en la liberación de todos los presos políticos y sociales, la derogación de las leyes represivas y la disolución de la DIPA, y la afirmación de relaciones con países que en América Latina, Europa y Asia corporizan aspiraciones emancipadoras, antiimperialistas (sic) y pacifistas similares a las del pueblo argentino. (El ICUF y el país. La Federación de Entidades Culturales Judías se pronuncia sobre la nueva realidad nacional. Tiempo, 57, 4, junio de 1973) 
A través de la solicitada, el ICUF se posicionaba públicamente frente a los "nuevos aires" que el triunfo de Cámpora simbolizaría marcando algunos de los tópicos que caracterizarían los posicionamientos icufistas durante el período: considerarse a sí mismos como los representantes de los sectores judíos "democráticos" y "progresistas"; destacando que la "causa judía" estaba implicada en las luchas de carácter más general; festejando las medidas "anti represivas"; y, especialmente, celebrando las relaciones que Argentina mantendría, en el plano internacional, con países de "aspiraciones emancipadoras, antiimperialistas y pacifistas”. (“El ICUF y...”, Tiempo, 57, Op. Cit.)

En este sentido, el ICUF se hacía vocero de "ese estado de espíritu colectivo", para destacar que frente a este nuevo jalón de la historia política argentina, sus organizaciones adheridas se consagraban como: 1) antidictatoriales- "a despecho de las limitaciones y restricciones que tal actitud combativa pudo haberle acarreado"-, 2) resueltas a participar "en las luchas democráticas del pueblo argentino"- "en oposición a la dirección sionista que, arrogándose una ficticia representatividad absoluta, postulaba la prescindencia ante los graves y decisivos enfrentamientos nacionales"-, 3) identificadas activamente "con los objetivos de democratización y reestructuración anti oligárquica y antiimperialista". ("El ICUF y...", Tiempo, 57, Op. Cit.)

Sin embargo, pese a las declaraciones festivas, la solicitada comenzaba a denunciar lo que, más adelante, sería una característica general del período: la acción de organizaciones de derecha.

Pero esa misma comunión justifica igualmente la inquietud que provoca en el seno de la colectividad el resurgimiento de organizaciones de muy triste memoria y de núcleos que pretenden erigirse en árbitros exclusivos de la nueva situación, y no por lo que puedan significar en sí mismas, en cuanto a número e influencia, sino como expresión particularizada de las fuerzas que esta poniendo en juego la reacción pro- 
oligárquica y pro-imperialista, dentro y fuera de las esferas gubernamentales, para intentar frenar el proceso de recuperación democrática y reestructuración social que el pueblo y el país demandan. (“El ICUF y...”, Tiempo, 57, Op. Cit.)

A través de la columna Tiempo Argentino, cuya autoría se encontraba bajo la pluma de Grisha Weltman ${ }^{10}$, se problematizaría el proceso de degradación de la institucionalidad democrática que sufriría Argentina a lo largo del trienio 1973-1975. Las alteridades, conflictos y tensiones suscitadas por las disputas al interior del partido gobernante serían considerados como un alejamiento de las pautas programáticas consagradas tras el triunfo electoral de Cámpora el 11 de marzo de 1973. De esta manera, la renuncia de Cámpora a la presidencia, en pos de facilitar un nuevo escrutinio que consagre el liderazgo de Perón, será entendida como "una imposición originada en las fuerzas más derechistas y retrograda del policlasismo justicialista, vista con buenos ojos por grupos similares de otros partidos, fuera del gobierno, y estimulada visiblemente por los sectores más reaccionarios del Ejército". (Weltman, G. (1973). Un golpe de timón a la derecha. Tiempo, 58, 5)

No obstante, la lectura programática del ICUF sería consecuente con la del $\mathrm{PCA}^{11}$ : el XIV Congreso Nacional Partidario definió positivamente al gobierno peronista por su carácter "reformista burgués". Decidiendo, asimismo, apoyar la candidatura de Perón en las elecciones a realizarse en septiembre de 1976, aunque destacando que la conducta del Partido sería la de "apoyar lo positivo y criticar lo negativo" (Cernadas y Tarcus, Op. Cit.). En consecuencia, el ICUF consideraría que las próximas elecciones serían la oportunidad de renovar el compromiso asumido por el peronismo tras la victoria de la fórmula Cámpora-Solano Lima:

\footnotetext{
${ }^{10}$ Como se conocerá en números posteriores, Grisha Weltman era el nombre en yidish de Gregorio Gelman. Ver "Goyo", Revista Tiempo, N¹26, julio de 1979, p.5.

${ }^{11}$ Sin embargo, durante la contienda electoral que consagró a Héctor Cámpora como Presidente de la Nación, el PCA había formado parte, junto al Partido Intransigente- liderado por Oscar Alende- y el Partido Revolucionario Cristiano -conducido por Horacio Sueldo-, de la Alianza Popular Revolucionaria (APR). Ilusionados, como señalan Cernadas y Tarcus, de jugar un papel clave como tercera fuerza en un supuesto ballotage entre el FREJULI y la Unión Cívica Radical (UCR), a favor de estos últimos. (Cernadas y Tarcus, Op. Cit)
} 
He aquí por qué el acto comicial del 23 de setiembre no significa elegir únicamente al Presidente y Vice de la República, sino también y sobre todo hacer de él una jornada de lucha más por lo que se jugó el 11 de marzo para impedir que las derechas, cualquiera sea su índole, levanten nuevamente la cabeza y por llevar a fondo las pautas programáticas que se dieron a conocer entonces, algunas de las cuales tuvieron andamiento gracias a la presencia del pueblo en su aplicación. (...) Es comprendiendo la gravedad de la situación que afrontamos, la necesidad de impedir el continuismo a través de un presunto gobierno de "conciliación” nacional, a cuyo amparo la oligarquía y los monopolios se mantengan en sus posiciones clave; es en aras de congeniar a todas las agrupaciones dispuestas a proseguir el cambio iniciado el 25 de mayo y de acelerar el proceso que gana día a día a las grandes masas laboriosas de la República en su lucha por la liberación y el socialismo, que el XIV Congreso del Partido Comunista realizado legalmente hace pocos días resolvió votar en setiembre por la candidatura peronista a la presidencia de la Nación. (Weltman, G. (1973). Por la liberación. Contra la dependencia. Tiempo, 59, 6)

Como señala De Riz, el 23 de septiembre de 1973 fue "un plebiscito sin sorpresas" (De Riz, Op. Cit. p.142). Juan Domingo Perón obtuvo la presidencia con el 62\% de los sufragios. En las páginas de revista Tiempo, sin embargo, la victoria se vio opacada. No por arrepentimientos, sino porque pocos días antes del escrutinio había tenido lugar, en el vecino país de Chile, el golpe militar que destronara de la presidencia a Salvador Allende. ${ }^{12}$

\footnotetext{
${ }^{12}$ La editorial de Tiempo comprendía el golpe pinochetista desde la acuciante amenaza que significaba la instalación de un régimen fascista en el Cono Sur: "Los acontecimientos chilenos conmovieron profundamente a los sectores populares de la colectividad judía del país. No fue desdeñable su concurso a las diversas y multitudinarias manifestaciones de protesta contra el golpe fascista y de solidaridad con el agredido y combatiente pueblo hermano. (...) Se explica esta presencia amplia y activa. Porque duele a las masas judías -como a las masa argentinas, en su conjunto- la brutal interrupción de una experiencia liberadora con
} 
Las repercusiones que tuviera el acontecimiento en Argentina -las declaraciones, movilizaciones y actos de solidaridad y repudio- fueron reivindicadas por Grisha Weltman como visibles manifestaciones "bajo el signo de la lucha contra la dependencia, por la liberación; bajo el signo de la patria socialista". (Weltman, G. (1973). Triunfar de la Ignorancia, de la Pobreza, del Atraso. Tiempo, 60, 5)

No obstante, el triunfo de Perón, aún frente a la amenaza que significaba el golpe pinochetista para la región, era comprendido como un paso victorioso:

El resultado de las elecciones (si bien previsto en cuanto al triunfador, no lo era tanto en relación al porcentaje de votos alcanzado por la lista del Frente Justicialista) revela la existencia en el seno del pueblo argentino de poderosas fuerzas obreras, populares, democráticas y patrióticas artífices de esa victoria- en la que colaboraron los comunistas y otras agrupaciones de izquierda- con cuyo respaldo el nuevo gobierno podrá llevar adelante exitosamente el programa de la liberación nacional, a poco que se unifique a todos los argentinos alrededor de esta plataforma para que entre todos arreglen el país que si no “no lo arregla nadie” (Perón). (Weltman, G. “Triunfar de la...”, Op. Cit.)

El optimismo icufista respecto de la victoria de Cámpora y la revitalización programática que significaba el triunfo de Perón, sin embargo, contrastan con la mirada que otros actores, incluso aquellos enrolados en las filas del peronismo, comenzaban a tener respecto de los destinos políticos del gobierno. Si bien el "retorno" de Perón fue bienvenido como una forma posible de reorganizar el poder del Estado y neutralizar la conflictividad política,

la que simpatizaban entrañablemente; porque detectaron de inmediato los rasgos más monstruosos del fascismo en el golpe descargado por el imperialismo y la reacción oligárquica contra el emancipado pueblo chileno; porque su propia experiencia histórica les recuerda que la caída de la República Española concluyó a la postre con el exterminio de seis millones de judíos; porque intuyen que lo de Chile entronca en lo de Bolivia y Uruguay y enfila contra nuestro propio país, donde el pueblo movilizado se capacita para librar definitivas batallas antiimperialistas y antigorilas". (Tiempo, 60, 1, setiembre de 1973) 
algunas de las facciones cercanas al peronismo $\mathrm{y}$, sobre todo a la izquierda peronista, comenzaban a desconfiar de la vocación conciliadora del líder. Sus intentos por encauzar la radicalización política al interior del propio movimiento, lo enfrentaba con nuevos desafíos.

A poco de consagrarse Perón en las elecciones de septiembre, era asesinado el Secretario General de la Confederación General de Trabajo (C.G.T), José Ignacio Rucci. El asesinato, como indica De Riz, evidenciaba, en primer lugar, que el camino de la reconciliación estaba sembrado de obstáculos inéditos. En segundo término, que las facciones en disputa al interior del peronismo, no estaban dispuestas a abandonar la confrontación que Perón mismo había estimulado (De Riz, Op. Cit. p.144). Si bien, la prédica icufista comenzó a poner el acento en el significado que tenían esta serie de "crímenes políticos", desde la revista Tiempo no se menoscababan los criterios optimistas hacia las políticas de gobierno. Incluso, cuando asumiera la presidencia de la Nación -una vez fallecido Juan Domingo Perón, el $1^{\text {o }}$ de julio de 1974- María Estela Martínez de Perón.

Esta es la hora de afianzar la legalidad instituida, el régimen democrático y representativo de gobierno, a la vez que se prosigue con todos los pasos positivos emprendidos por Perón durante el corto lapso de su presidencia, tanto en el orden internacional como en el interno. Libertades democráticas; leyes económicas progresistas para favorecer al pueblo trabajador y los intereses nacionales contra la política agresiva de los monopolios y la oligarquía nativa, política exterior independiente, afirmando la apertura iniciada hacia Cuba y los países del Este, favoreciéndonos con su intercambio para afianzar la propia soberanía con vistas a la liberación. ${ }^{13}$ (Weltman, G. (1974). Independencia y libertad. Tiempo, 69, 5)

\footnotetext{
${ }^{13}$ Resulta significativo que, en varias oportunidades, los redactores de Tiempo destacan como una política de carácter "progresista" las relaciones diplomáticas y comerciales que Argentina sostiene, durante el período, con Cuba, los países comunistas de Europa del Este y la URSS. Por ejemplo, ver Grisha Weltman: "Ninguna
} 
Los comentarios sobre el carácter "progresista" y "democrático" de las políticas gubernamentales contrastan con los informes e interpretaciones que los redactores del mensuario icufista producían en torno del incremento de la violencia política. Si bien condenaban los atentados de las organizaciones de "ultraizquierda"-por alentar la desestabilización y la contraofensiva de las agrupaciones fascistas ${ }^{14}$-, la preocupación mayor estuvo centrada en la emergencia y vigor que cobraban las organizaciones de derecha- las cuales, como señala Tiempo en varias oportunidades, contaban con la anuencia oficial.

Pero, asimismo, al denunciarlo develaban el carácter insurreccional de estos grupos y la amenaza que significaban para la institucionalidad democrática. En este sentido, lo acontecido en Chile con el gobierno de Salvador Allende, servía en más de una oportunidad para "visualizar" los riesgos de no enfrentar a las organizaciones de derecha.

En cuanto al desarrollo de la política nacional cabe preguntarse si en verdad "las cosas marchan bien" como asegurara no hace mucho el ministro Llambí. Desde el 12 de octubre a esta parte, las fuerzas derrotadas el 11 de marzo, replegadas en un comienzo ante el triunfo popular, han vuelto a levantar la cabeza y pasan a la ofensiva (...) Las contradicciones internas del partido gobernante se trasladan así a las esferas oficiales parlamentarias y gremiales como lo traducen las leyes de prescindibilidad, de

Ley represiva o retrograda", Tiempo, 64, 5, enero de 1974; Weltman, G. (1974). Peligra la institucionalidad del País. Tiempo, 65, 5.

${ }^{14}$ Por ejemplo, un recuadro en el que se destaca que "cualesquiera sean los instigadores y ejecutores (de José Ignacio Rucci), es indiscutible que el crimen está objetivamente al servicio de la contrarrevolución (...) Quizás no sea casual que el atentado terrorista se haya producido a poco más de 24 horas del pronunciamiento comicial en el que la abrumadora mayoría del pueblo argentino reafirmó su decisión de cerrarle el camino a la conspiración oligárquico-imperialista y ensanchar los grandes cambios progresistas en la realidad nacional". (Rucci. Tiempo, 60, 5, septiembre de 1973). De carácter más definido se puede encontrar la crítica al copamiento del Regimiento militar de la localidad de Azul, en la provincia de Buenos Aires, por parte del Ejército Revolucionario del Pueblo (E.R.P): "Importa poco el signo que exhiban o les atribuyan, lo cierto es que los responsables y ejecutores de la sangrienta provocación en la guarnición militar de Azul ha actuado deliberadamente en conformidad con los objetivos del enemigo oligárquico-imperialista de la liberación nacional y del proceso democratizador iniciado a raíz de la derrota electoral de la dictadura. (...) Si los inspiradores del ataque terrorista fueran de ultraizquierda, no pudieron dejar de prever esa derivación reaccionaria de su intentona (...) Urge oponerse decididamente a esa presión antidemocrática tendiente a enchalecar (sic) a las fuerzas populares y facilitar la acción del golpismo fascista". (La provocación de Azul. Tiempo, 64, 8, enero de 1974) 
Asociaciones Profesionales, de radicación de capitales extranjeros, entre otras, o la ofensiva de la jerarquía sindical contra militantes y gremios combativos como el que dirige Tosco en Córdoba (...) Por eso Lorenzo Miguel apestilló a los parlamentarios peronistas para que voten incondicionalmente la reforma a la ley de Asociaciones Profesionales, a cuya cuenta hay que cargar el ignomioso atentado contra el senador radical Dr. Hipólito Solari Yrigoyen, como lo denuncian desde diversos sectores, haciéndose aún más evidente la existencia de elementos para-policiales, que tienen la inmunidad para secuestrar y martirizar a militantes gremiales, a gente de la juventud trabajadora peronista, cuando no de asesinar a mansalva, ametrallar locales, etc. Las fuerzas democráticas, de izquierda, políticas, sociales y gremiales tendrán que asumir su auto-defensa masiva frente a los atropellos cuya autoría parecen ignorar las fuerzas de seguridad por la impunidad con que se perpetran" (Weltman, G. (1973). Urgencia con las pautas programáticas. Tiempo, 62, 5-6)

Un mes después, en las vísperas de 1974, desde la revista Tiempo se hacía un llamamiento para volver al programa refrendado el 11 de marzo de 1973:

Estamos en vísperas del Año Nuevo. So pretexto de algún secuestro o acto de violencia de presunta izquierda (que objetivamente no ayuda para nada al proceso revolucionario y más bien favorece los planes de la derecha) no se puede hacer la vista gorda sobre los asesinatos y las depredaciones de las bandas armadas que, impunemente, se adelantan como en Chile- a las medidas reaccionarias que se proponen asumir los golpistas del gorilaje y la derecha conspiradora, cuyos planes son cada vez más osados y notorios (...) En defensa de la legalidad democrática alcanzada en este año, de mejores condiciones de vida y de trabajo, de la economía y el patrimonio nacional, de una política latinoamericana antiimperialista y de más amplias relaciones exteriores con todo el mundo, es posible y urge ensanchar la brecha abierta el 11 de marzo y desplegar la 
unidad de todas las fuerzas y agrupaciones democráticas para aplastar la alimaña fascista en 1974 y promover con más coraje y decisión los cambios conducentes a la liberación nacional y social. (Weltman, G. (1973). 1974, año de la consolidación de la legalidad y la liberación. Tiempo, 63, 6)

La "unidad de todas las fuerzas y agrupaciones democráticas contra la alimaña fascista", serviría, en primer lugar, a los fines de la propuesta programática icufista para confrontar contra aquellos que tenían una prédica encendidamente anticomunista. Pero, en segundo término, porque las denuncias sobre el accionar "comunista" y/o "subversivo" era asociado, por estas organizaciones, a conceptos como "sinarquía", "sionismo" y "judaísmo". Con el expreso designio de señalar a los "enemigos" del proceso de liberación nacional que significaba el "retorno" del peronismo, como señala Senkman, se esgrimió el uso del concepto de "sinarquía" como pretexto para denunciar tanto la dependencia, la infiltración de la "Patria Socialista" en el cuartel de la "Patria Peronista", así como responsabilizar a Montoneros del asesinato de Rucci o para denunciar a Gelbard, Ministro de Economía de los gobiernos de Cámpora y Perón. ${ }^{15}$ (Senkman, 1989, p.112)

Los redactores de Tiempo se vieron interpelados por este doble componente que caracterizó la prédica de los grupos de derecha: su retórica anticomunista y antisemita:

\footnotetext{
${ }^{15}$ Según Senkman, "La sinárquica conspiración estaba condensada para estas revistas de derecha en la figura del ministro Gelbard. Este judío polaco naturalizado y hombre de confianza de Perón, representaba por un lado, el proyecto de la burguesía y el empresariado nacional sindicalizado en torno de la Confederación General Económica, que logró desplazar del poder político a la tradicional Unión Industrial y Sociedad Rural Argentina. Pero también era percibido por El Caudillo, Enlace, Consigna Nacional y el resto de la prensa peronista de ultraderecha como el peligroso aliado de la izquierda, por ser simpatizante de las democracias socialistas a las cuales buscó el ministro de Economía abrir el mercado argentino. Su condición de judío y las vinculaciones que lo unían con otros prominentes empresarios nacionales judíos como Bronner, Timerman, Madanes y Graiver, fue utilizada por esos sectores antisemitas para potenciar y promover una campaña política en contra de ese proyecto socio-económico del peronismo a partir del uso fantasmagórico del supuesto infiltrado sinárquico en las filas mismas del Movimiento Nacional Justicialista". (Senkman, 1989, pp. 123-124). Para una historia del concepto de sinarquía en Argentina, ver Bohoslavsky, E. (2008).
} 
El presidente Perón dio, no hace mucho, seguridades a una delegación de la DAIA, en el sentido de que jamás tolerará el antisemitismo en las filas del movimiento que lidera. Contradicen y se levantan contra Perón, por lo tanto, los que abierta o solapadamente difunde el prejuicio antijudío desde posiciones partidarias o gubernamentales. Y curioso es que los que así lo hacen se proclamen precisamente "soldados de Perón" en la ofensiva macartista contra la izquierda dentro y fuera del justicialismo (...) El ministro de Bienestar Social, López Rega, cuya gravitación en la ofensiva derechista es conocida, tuvo expresiones confusas y equívocas referidas al origen judío de "funcionarios gubernamentales" (en evidente alusión al ministro de Economía, en relación con su tan exaltada y promocionada camaradería con el furioso chovinista libio Qaddafi). "El Caudillo" vocero del extremismo derechista del peronismo, incluye en una alucinante y provocativa lista de organizaciones subversivas a varias instituciones judías, tanto sionistas como progresistas. Hechos todos estos que confirman que la conspiración de la derecha contra el rumbo progresista abierto por el triunfo popular del 11 de marzo viene acompañada de un conocido e inconfundible tufo antisemita. Lo cual significa que la lucha contra la amenaza antijudía y la defensa de la colectividad pasa por la lucha contra el complot de la derecha y en defensa de las conquistas democráticas del pueblo argentino. (La derecha es antisemita. Tiempo, 65, 6, febrero/marzo de 1974)

A lo largo del trienio se pueden registrar en las páginas de Tiempo una cuantiosa información acerca de atentados y amenazas de carácter antisemita que pusieron en vilo la vida comunitaria judía en Argentina: entrevistas televisivas a dirigentes e intelectuales 
nacionalistas ${ }^{16}$; pintadas agraviantes contra la figura de José Ber Gelbard ${ }^{17}$, Ministro de Economía; un acto celebratorio del $38^{\circ}$ aniversario de la Alianza Libertadora Nacionalista ${ }^{18}$; el descubrimiento de un "orden del día" de la Policía de la provincia de Río Negro en la que se alertaba sobre la acción de "masones, judíos y comunistas"19; atentados y pintadas de svásticas en sedes de instituciones judías de las provincias de Mendoza, Córdoba, Buenos Aires y Capital Federal ${ }^{20}$; declaraciones acerca de los barrios "El Once" y "Villa Crespo" como "barrios de la usura", por parte de dirigentes peronistas ${ }^{21}$; el atentado a la institución de la red escolar del ICUF "J. Zhitlovsky",22 y el ataque perpetrado contra Mirta Judewicz, docente de la escuela "I. L. Peretz" de Villa Lynch ${ }^{23}$, son algunos de los más significativos.

No obstante, la prédica sobre el antisemitismo permitía a los redactores del mensuario icufista, por un lado, agudizar su crítica a las facciones "fascistas" y de derecha que destilaban un "tufo antisemita". Por el otro, confrontar con la dirigencia comunitaria; sobre todo aquella que se concentraba en instituciones públicamente reconocidas como representativas de la comunidad judía: la Delegación de Asociaciones Israelitas de Argentina (DAIA). En este sentido, si bien la revista Tiempo se encontraba próxima a los enunciados del PCA- como se puede observar en las apreciaciones realizadas por Cernadas y Tarcus (Op. Cit.)- no puede menospreciarse que los integrantes del ICUF disputaban sentidos y "auditorio" con otras instituciones de la comunidad judía de Argentina.

Cada convocatoria a "combatir" la embestida contra la institucionalidad democrática era motivo, a su vez, para deslizar críticas hacia la dirigencia sionista. Por ejemplo, frente al golpe militar ocurrido en la República de Chile, los redactores de Tiempo consideraban:

\footnotetext{
${ }^{16}$ Antisemitismo en el 7. Tiempo, 66, 1-2, abril de 1974.

${ }^{17}$ Otra vez el Judeo-Comunismo. Tiempo, 69, 1-2, julio de 1974.

${ }^{18}$ Otra vez la "Alianza". Tiempo, 71, 6, septiembre de 1974.

${ }_{19}$ Antisemitismo a la orden del día. Tiempo, 74, 5, diciembre de 1974.

${ }^{20}$ Neofascismo. Tiempo, 77, 1-2, abril de 1975. Antisemitas en Mendoza. Informe de la Coordinadora Juvenil del ICUF. Tiempo, 77, 9, abril de 1975.

${ }^{21}$ Todos juntos podremos. Tiempo, 79, 1-2 junio de 1975.

${ }^{22}$ Repudio unánime al atentado terrorista. Tiempo, 79, 4-5, junio de 1975.

${ }^{23}$ Vandálico ataque contra una Maestra del ICUF. Tiempo, 81, 1-2 y 9, agosto de 1975.
} 
La "Daia" chilena se manifestaba "prescindente" ante la amenaza del fascismo. Pero no lo fue. Un día después, el 12 de agosto, realizaba un acto contra la URSS y hacía pública una declaración "en nombre de la colectividad judía" que aportaba lo suyo al clima antisoviético y anticomunista que el gorilaje golpista se esforzaba en crear entre vastos de las clases medias al oponerlas al régimen popular (el 11 de agosto el Comité Representativo de la Colectividad Israelita de Chile emitió una declaración repudiando “a quienes intentaban confundir a la opinión pública manifestando que la colectividad israelita estaba a favor o en contra de un determinado régimen"). Ahora, los sectores populares judíos chilenos, individual y colectivamente, son víctimas del tremendo crimen. Que la "Daia” de allá asuma su responsabilidad (...) ¿Extraerá conclusiones la "Daia" de aquí del sangriento drama de Chile? También ellas se declararon "prescindentes" ante los grandes enfrentamientos nacionales entre la democracia y la reacción, entre la liberación y la dependencia. Nada dijo hasta ahora sobre el fascismo entronizado en la República hermana. No vimos sus carteles en las grandes movilizaciones populares de solidaridad. La "Daia" se atribuye la representatividad comunitaria; ¿debemos suponer, entonces, que a criterio de sus dirigentes, la colectividad como tal, a través de sus organizaciones, deba mantenerse al margen, permanecer indiferente ante la monstruosa conspiración contra la democracia, la libertad, el futuro progresista del pueblo argentino y de todos los pueblos latinoamericanos? (Unidad en la solidaridad. Tiempo, 60, 1-2, septiembre de 1973)

Pese a las palabras e interrogantes planteados por el editorialista de Tiempo, el devenir de la conflictividad político movió a la DAIA a posicionarse públicamente a favor de la 
continuidad institucional tras el fallecimiento del presidente Juan Domingo Perón. Sin embargo, para los icufistas, las declaraciones de la DAIA no concordaban con su accionar posterior: al igual que la "Daia chilena" su prédica anti-soviética estaba al servicio de la "reacción". ${ }^{24} \mathrm{O}$, también, tras una serie de operativos policiales en la provincia de Córdoba, en los cuales aparecieron pintadas alusivas a la Triple A en los locales partidarios allanados, los redactores de Tiempo refieren a la "prescindencia" de DAIA que no denunciaba los atropellos que se cometen contra la sociedad civil. ${ }^{25}$ Incluso, en el caso de la Asociación Mutual Israelita de Argentina (AMIA), se condenaba su silencio en la celebración de su $80^{\circ}$ aniversario frente a lo que ocurría en Argentina:

Mientras tanto en nuestro país están ocurriendo cosas serias. La derecha pro fascista acentúa sus presiones para torcer el rumbo progresista iniciado hace un año por el pueblo argentino, no descartando en el proyecto un golpazo a la chilena, y sin abstenerse, en los recursos propagandísticos y psicológicos, para crearse un clima propicio, del uso de elementos ostensiblemente antisemitas. Durante los festejos de la AMIA, nada se dijo al respecto. Y no quisiéramos creer que se especule con ello para favorecer la misión del señor Sapir. Sería una nueva prueba de su divorcio con los sentimientos e intereses de la colectividad, vivamente incorporada a la lucha patriótica por desbaratar la conjura de la derecha. ${ }^{26}$ (La AMIA dicotómica. Tiempo, 70, 1, agosto de 1974)

Esta serie de denuncias tendientes a poner en cuestión las acciones y posicionamientos públicos de la dirigencia comunitaria -particularmente aquellas que se concentraban en

\footnotetext{
${ }^{24}$ Otra vez el Judeo-Comunismo. Op. Cit. Palabras similares, asociando los discursos antisoviéticos de DAIA con el fascismo de las organizaciones de derecha, aparecen en Neofascismo, Op. Cit.

${ }^{25}$ Que las A no lleguen a la Z. Tiempo, 72, 4, octubre de 1974.

${ }^{26}$ Pinchas Sapir fue el funcionario israelí, entre los años 1955 - 1974, a cargo del ministerio de Industria, primero, y de Economía después. Los "tiempos de Sapir" son los años donde se estructuró, construyó y cimentó la economía floreciente israelí.
} 
DAIA y AMIA- se contraponía a lectura que del conflicto político argentino realizaban los dirigentes icufistas. Sus llamados a la "unidad de las agrupaciones democráticas y progresistas" para enfrentar a "las fuerzas de la reacción", que eran anticomunistas y antisemitas, eran una constante en el análisis de la información y los postulados programáticos de Tiempo. Pero, justamente, porque uno de los componentes de las fuerzas de la "reacción" era el antisemitismo, las convocatorias icufistas resultaban ser, en oportunidades, llamamientos a los jóvenes militantes de las organizaciones sionistas.

En este sentido, como señala Krupnik (2011), los movimientos juveniles judíos sionistas no estuvieron al margen del proceso de radicalización política que caracterizaron a las décadas del sesenta y setenta en Argentina. Jóvenes del Hashomer Hatzair, por ejemplo, ampliaban sus márgenes de discusión, acción y militancia, llegando a constituir organizaciones con una fuerte inserción en el campo universitario y, en oportunidades, participando de organizaciones político-militares. ${ }^{27}$ Esas perspectivas, al interior del campo judío, también enfrentaron a los redactores de Tiempo con los dirigentes de las instituciones centrales de la comunidad judía.

La referencia más directa se encuentra en la nota editorial de la revista icufista cuando, a raíz de la asunción de la presidencia de la DAIA, a fines de 1973, el Dr. Nehemías Resnizky se pronuncia críticamente respecto de la falta de diálogo entre los jóvenes y los adultos de la colectividad judía. En esta oportunidad, la nueva autoridad promociona el fantasma de la asimilación de los jóvenes judíos frente a la "seducción" de participar en la contienda política nacional. Frente a esta propuesta, los redactores de Tiempo consideran que:

Es verdad que existe un profundo proceso de asimilación de la colectividad, pero de ninguna manera significa ello la “desintegración espiritual” de la misma. Se trata de un

\footnotetext{
${ }^{27}$ Por ejemplo, en Córdoba, una escisión del Comité de Coordinación -una organización sionista de izquierdala "Línea Sionista Socialista" y más tarde Amós, mantuvo contactos con una de las organizaciones políticomilitares que protagonizaron la escena de radicalización política durante el período: el Ejército Revolucionario del Pueblo (ERP).
} 
proceso objetivo, histórico e incontenible que se produce precisamente porque la colectividad no es un "cuerpo extraño" ni vive de "espaldas" a los intereses del pueblo argentino (...) Es verdad también -con las precisiones que daremos enseguida- que hay un "enfrentamiento generacional" y que "no hay diálogo entre nosotros y nuestros hijos". Es verdad, no en la forma en que esta dicho, sino en lo que realmente quiere significar. La inmensa mayoría de la juventud de origen judío se integra -como bien lo apunta el presidente de la DAIA- en las corrientes políticas generales; pero no en cualquier corriente política, sino en las que de una u otra manera expresan las necesidades revolucionarias de la situación argentina y las transformaciones emancipadoras y socialistas, en la arena mundial (...) No hay diálogo entre padres e hijos cuando los padres "están de espaldas" a ese proceso revolucionario por el que tan ardorosamente pelea la juventud (...) Pero, al margen de estas disquisiciones, lo que evidentemente preocupa a la dirección sionista de la DAIA no es la "evaporización" de la vida judía, sino la militancia progresista de los que supuestamente se "evaporan". (Acerca de la identidad judía. Tiempo, 64, 3-4, enero de 1974)

Exaltación de la "juventud” y la "militancia” serán parte de los tópicos que caracterizará la prosa icufista durante el período. En las páginas de Tiempo será común encontrar solicitadas, comunicados o informes de la "Juventud Progresista Judeo-Argentina" ${ }^{28}$ Pero, denodadamente, la participación de los sectores juveniles será celebrada como el producto de la prédica "progresista" que al interior de la comunidad judía encarna el ICUF.

\footnotetext{
${ }^{28}$ Declaración en ocasión de estar reunida la Juventud Juedo-Argentina en su máximo evento ICUFIADA '73. Tiempo, 59, 13, agosto de 1973; Comunicado de la Juventud Progresista Judeo Argentina. Tiempo, 64, 25, enero de 1974; Convoca el Comité 19 de Abril: Rindamos nuestro homenaje a los héroes del Ghetto de Varsovia. Tiempo, 66, 13, abril de 1974; El plenario nacional de la Juventud del ICUF. Tiempo, 68, 11, junio de 1974; Antisemitas en Mendoza. (Informe) de la Coordinadora Juvenil del ICUF. Tiempo, 77, 9, abril de 1975.
} 
Evidenciando una "victoria" frente a los sectores sionistas que se consideran "prescindentes" de su participación pública en la política local, regional o nacional.

En ciertos sectores de la izquierda sionista local, particularmente de la juventud, se están insinuando reacciones saludables a los insistentes intentos del movimiento progresista de tender puentes hacia las masas democráticas de la colectividad influenciadas por el nacionalismo judío (...) Previsto, decimos, porque una serie de factores está operando en los últimos tiempos en la sensibilidad y conciencia de la gente honesta, objetivamente integrada en el mundo del progreso por sus tradiciones y su posición social, pero sometida durante un largo período a una feroz y diversificada presión psicológica e ideológica por parte de la dirigencia reaccionaria del sionismo. Entre tales factores podríamos destacar los siguientes: la creciente radicalización y combatividad de las juventudes y clases medias y su decidida participación en las luchas emancipadoras del pueblo argentino; la preeminencia de las ideas nacional-liberadoras en el país y en el mundo y el indiscutible liderazgo de los acontecimientos internacionales asumido por el campo socialista, encabezado por la Unión Soviética; el profundo descrédito en que ha caído el gobierno de Israel y la dirección sionista, y la revelación cada vez más neta de los rasgos regresivos de su política desde siempre denunciados por los movimientos progresistas... (El diálogo es posible. Tiempo, 59, 1, agosto de 1973)

No obstante, la prédica optimista respecto de la militancia y el compromiso de los sectores juveniles y la narrativa sostenida referente a garantizar la estabilidad institucional y convocar a la unidad de los "sectores progresistas y democráticos", comienza a resquebrajarse hacia mediados de 1975. La crisis política del gobierno de María Estela Martínez de Perón y la degradación de la alternativa institucional democrática sería 
reflejada en las editoriales de la revista. Como se mencionó anteriormente, en las páginas de Tiempo se agudizaron las críticas a los atentados y la escalada de violencia política que acrecentaron los sentidos acerca del final de la institucionalidad democrática. ${ }^{29}$

Cuanto más se aleja la primera mandataria de la plataforma política que votó la fórmula del peronismo una gran parte de la ciudadanía en 1973, tanto más audaces se presentan los voceros y fautores (sic) del golpe y proclaman cada día más abiertamente sus intenciones de quebrar la legalidad institucional, las derechas reaccionarias y fascistas (...) Todo esto y mucho más no sería posible y estaría a buen recaudo si el gobierno y la señora M. E. Martínez de Perón se hiciera eco del clamor general, del planteo de las agrupaciones políticas y sociales democráticas y aún de ciertos círculos y representantes del partido oficialista que, como las fuerzas armadas, la Iglesia y la inmensa mayoría del país afirman su disposición a colaborar en la conducción de la nave del Estado a buen puerto. (Weltman, G. (1975). El peligro de la quiebra institucional. Tiempo, 84, 5)

Esta última editorial alusiva al tema, antes de que se concretase el asalto del poder por las Fuerzas Armadas, el 24 de marzo de 1976, sintetizaba la postura programática del ICUF. Posicionamiento que, como señalan Cernadas y Tarcus (Op. Cit), era afín al del PCA: diferenciándose públicamente de lo que consideraba la "ultraizquierda", bregaba por formulas institucionales que se tradujeran en el recorte del poder efectivo de la Presidente y su entorno "lopezrreguista", constituyendo un gabinete producto de una coalición cívicomilitar "progresista” que se ajustara a las "pautas programáticas” refrendadas en 1973.

\footnotetext{
${ }^{29}$ Weltman, G. (1975). La crisis está enervando a todo el país, y Solicitada: Icuf y el momento actual. Tiempo, 81, 4, 6 y 22.
} 


\section{Algunas consideraciones finales}

Las páginas de Tiempo, durante el período analizado, están repletas de llamamientos en pos de sostener la legalidad democrática e institucional inaugurada tras la victoria de la fórmula Cámpora-Solano Lima. Pero, como se preguntan Cernadas y Tarcus en relación al PCA, a quiénes estaban dirigidas esas interpelaciones. En el caso del Partido, como señalan los autores, los interlocutores serían los "partidos democráticos y populares". ${ }^{30}$ No obstante, la particularidad de Tiempo resulta de comprender el amplio campo de interlocutores o "juego de traducciones" de los enunciados del PCA para un público perteneciente a la comunidad judía.

El trabajo con las páginas de Tiempo evidenció que la posición del ICUF en relación al devenir de la conflictividad política e institucional en Argentina se hallaba en sintonía con las resoluciones partidarias. Sin embargo, como se mostró a lo largo del artículo, los posicionamientos de los redactores del mensuario icufista permitían interpelar, cuestionar o condenar a los sectores dirigentes -sobre todo de la DAIA- por sus acciones o su "prescindencia" en torno de los acontecimientos nacionales.

En este sentido, las representaciones sobre el golpe militar chileno evidenciaban, por un lado, los peligros de la amenaza fascista en Argentina. Y, en segundo término, permitía poner en tensión alguna de las prácticas realizadas por la dirigencia judía -particularmente la denuncia del régimen soviético por su carácter antisemita- que resultaban afines a la prédica anti-izquierdista de las agrupaciones de derecha.

Asimismo, las páginas de Tiempo resultan ilustrativas de uno de los tópicos acerca de los cuales la dirigencia comunitaria se vio interpelada: la deserción de muchos jóvenes que participaban de ambientes comunitarios y comenzaron a verse atraídos por las causas nacionales.

\footnotetext{
${ }^{30}$ Cernadas, Jorge y Tarcus, Horacio, Op. Cit.: 13.
} 


\section{Bibliografía}

Bohoslavsky, E. (2008). Contra la Patagonia judía. La familia Eichman y los nacionalistas argentinos y chilenos frente al Plan Andinia (desde 1960 hasta nuestros días). Cuaderno Judaico, 25.

Camarero, H. (2007). El mundo obrero judío comunista. En Camarero, H., A la conquista de la clase obrera. Los comunistas y el mundo del trabajo en la Argentina, 1920-1935. Buenos Aires: Siglo XXI.

Cernadas, J. y Tarcus, H. (2005). Las izquierdas argentinas y el golpe de Estado de 1976: el caso del Partido Comunista, ponencia presentada en el marco de las $\mathrm{XI}^{\circ}$ Jornadas Interescuelas/Departamentos de Historia, Universidad Nacional de Tucumán.

De Riz, L. (2000). La política en suspenso, 1966/1976. Buenos Aires: Paidós.

Dujovne, A. (2008). Cartografías de las publicaciones periódicas judías de izquierda en Argentina, 1900-1953. Revista del Museo de Antropología, 1 (1)

Guy, D. (1994). El sexo peligroso. La prostitución legal en Buenos Aires. Buenos Aires: Sudamericana.

Kahan, E. (2005). La identidad judía en la Argentina en los tiempos del "affaire Eichmann" (1961-1962). En Frederic, S. y Soprano, G. (Comps). Cultura y Política en etnografías sobre la Argentina. Bernal: Universidad Nacional de Quilmes.

Kahan, E. (2013). Entre Cámpora, Perón y Pinochet: la radicalización del discurso de las organizaciones judías argentinas. Revista Judaica Latinoamericana, 6. 
Kessler, B. (2008). Publicaciones, libros y bibliotecas en la colectividad judeo-progresista argentina. En Solari, T. y Gomez, J. (Comps.). Bibliocastía. Los robos, la represión y sus resistencias archivos y museos de Latinoamérica. Buenos Aires: EDUEBA.

Krupnik, A. (2011). Cuando camino al kibutz vieron pasar al Che. Radicalización política y juventud judía: Argentina 1966-1976. En Kahan, E. et al, Consagrados y marginados. Nuevos estudios sobre la vida judía en Argentina. Buenos Aires: Lumiere.

Lanusse, L., (2005). Montoneros. El mito de los 12 apóstoles. Buenos Aires: Vergara.

Lvovich, D. (2003). Nacionalismo y antisemitismo en Argentina. Buenos Aires: Vergara.

Schenkolewski-Kroll, S. (1993). La conquista de las comunidades: el movimiento sionista y la comunidad ashkenazi de Buenos Aires (1935-1949). En Judaica Latinoamericana, Estudios Históricos y sociales II.

Senkman, L. (1989). El antisemitismo bajo dos experiencias democráticas: Argentina 19591966 y 1973-1976. En Senkman, L. (Comp.). El antisemitismo en la Argentina. Buenos Aires: Centro Editor de América Latina.

Svarch, A. (2005). ¿Comunistas judíos o judíos comunistas? El activismo y la lucha de la rama judía del PC en un contexto de crisis identitaria, 1920-1950. Ponencia presentada en las X Jornadas Interescuelas/Departamentos de Historia, Rosario.

Yafitz, M. (2011). Prosopografía proxeneta: inmigración judía, socorros mutuos y comercio sexual en Argentina, 1906-1930. En Kahan, E. et al, Consagrados y marginados. Nuevos estudios sobre la vida judía en Argentina. Buenos Aires: Lumiere.

Visacovsky, N. (2015). Argentinos, judíos y camaradas tras la utopía socialista. Buenos Aires: Biblos. 
Zadoff, E. (1995). Historia de la Educación judía en Buenos Aires, 1894_1994. Buenos Aires: Milá. 